\title{
Die Strategiese Bestuur van Regstellende Aksie in Plaaslike Regering in Suid Afrika*
}

\section{P Brynard en E van Rooyen}

Skool vir Openbare Bestuur en Administrasie, Universiteit van Pretoria

\section{ABSTRACT}

The South African Government regards affirmative action as an important method to rectify the discriminatory career practices followed against Blacks, Coloureds, Indians and women under the previous political dispensation. Legislation and policy that provide for affirmative action in institutions have been formulated and are considered in this paper. After normative and empirical research, it is concluded that it is possible to develop strategic affirmative action programmes in local government institutions and that affirmative action can be managed in terms of a strategic process in local government. It is further concluded that managers in local governments play a key role in the successful implementation of strategic affirmative action programmes.

JEL D 630

\section{INLEIDING}

Ten spyte van die afskaffing van apartheid en die uiteindelike daarstel van 'n demokraties verkose regering in Suid Afrika, word die land se sosio-ekonomiese bedeling steeds gekenmerk deur rasse-, geslag-, religieuse- en klasseongelykheid. Die Suid Afrikaanse Regering het gevolglik die herstrukturering van die Suid Afrikaanse openbare sektor as een van sy primêre oogmerke gestel.

Herstrukturering, beskou teen die agtergrond van die Herophou en Ontwikkelingsprogram (HOP), verwys onder andere na regstellende aksie (Reconstruction and Development Programme, 1994: 9). Volgens die Heropbou en Ontwikkelingsprogram word die ontwikkeling van menslike hulpbronne in Suid Afrika met behulp van regstellende aksie gesien as 'n sleutelprogram vir die heropbou en ontwikkeling van die gemeenskap (Reconstruction and Development Programme, 1994:9).

- The Strategic Management of Affirmative Action in Local Government in South Africa 
Wêreldwyd word programme geloods met die oog op die uitwissing van verskeie soorte ongelykhede. Regstellende aksie is so "n program en word verskillend getipeer; terme soos regstellende maatreëls, positiewe diskriminasie, spesiale regte, standardisasie, seuns-van-die-grond-voorkeurreg en voorkeurbehandeling, is terme wat gereeld in literatuur aangetref word (Working Paper of the Constitutional Development Service, 1993). Voorbeelde hiervan word ook in plaaslike regerings aangetref. Die Stadsraad van Pretoria besig byvoorbeeld benewens regstellende aksie, ook nie-amptelik die term instaatstellingsaksie om hierdie instelling se regstellende aksieprogram te beskryf. Volgens die Stadsklerk v0an die Stadsraad van Pretoria (1996), is ' $n$ altematiewe beskrywing van die inhoud en oogmerk van die regstellende aksieprogram wat deur die Stadsraad geloods word, instaatstellingsaksie. Die Groter Johannesburg Metropolitaanse Oorgangsraad besig byvoorbeeld die terme regstellende aksie en gelyke geleenthede om hulle transformasieprogram te beskryf (Regstellende Aksieadviseur: Groter Johannesburg Metropolitaanse Oorgangsraad, 1996). In hierdie artikel word die konsep regstellende aksie verklaar en ' $n$ model voorgehou vir die strategiese bestuur daarvan in plaaslike regering.

\section{REGSTELLENDE AKSIE IN DIE VERENIGDE STATE VAN AMERIKA}

Die Verenigde State van Amerika se program van aktiewe regstellende aksie is een van die bekendste en oudstes ter wêreld (Development and Democracy, September 1993). Regstellende aksieprogramme het 'n wesentlike invloed op die openbare personeeladministrasie in die Verenigde State van Amerika gehad. Hofgedinge oor vermeende onbillike arbeidspraktyke kom gereeld voor. Getuienis daarvan word gevind in die vele hofsake wat die afgelope dertig jaar oor die onderwerp plaasgevind het (Andrews, 1992: 34). Gedurende die sestigerjare het die Verenigde State van Amerika geëksperimenteer met regstellende aksieprogramme en het innoverende denke oor die onderwerp posgevat. Die gevolg is dat verskeie sosiale gelykheidsprogramme met 'n mindere of 'n meerdere mate van sukses geïmplementeer is. Debatte is ondermeer gevoer oor die aanpassing van indiensnemingstandaarde, die wenslikheid van kwotastelsels en of indiensnemingsdoelwitte noodsaaklik is.

\section{REGSTELLENDE AKSIE AS 'N EIETYDSE SUID AFRIKAANSE VERSKYNSEL}

Regstellende aksie blyk nie 'n totaal nuwe idee in die Suid Afrikaanse milieu te wees nie. Gedurende die dertiger jare van die twintigste eeu is die blanke Afrikaner ook met behulp van 'n ekonomiese en sosiale bemagtigingsprogram 
opgehef (Adams ed. 1993). In die sewentiger jare het verskeie Suid Afrikaanse maatskappye byvoorbeeld in terme van die Sullivan-kode regstellende aksie toegepas (Madi, 1993: 5), Suid Afrikaanse instellings put egter tans heelwat idees en lesse oor regstellende aksie uit die Amerikaanse ondervinding. Kenners oor regstellende aksie en akademici vanuit die Verenigide State van Amerika, tree gereeld tydens Suid Afrikaanse seminare op. Sowel die openbare- as die privaatsektor maak van diegene se kundigheid op 'n konsultasiebasis gebruik ten einde hulle instellings te herstruktureer.

Die agtergrond waarteen Suid Afrikaanse instellings regstellende aksieprogramme implementeer, is uniek en pionierswerk word deurlopend in hierdie opsig verrig (Wingrove, 1993:vi). Een van die belangrikste verskille tussen Suid Afrika en die Verenigde State van Amerika se regstellende aksiebehoefte, handel oor wie die regstellende aksieteikengroep in die onderskeie twee lande is. In die Verenigde State van Amerika maak die regstellende aksieteikengroep 'n minderheids-bevolkingsgroep uit en in Suid Afrika maak die regstellende aksieteikengroep 'n meerderheidsbevolkingsgroep uit. Diegene wat hoofsaaklik deur 'n regstellende aksieprogram in Suid Afrika sal baat is swartes, bruinmense, Indiërs, vroue en gestremde persone. Tydens die ontwikkeling van geskikte regstellende aksieprogramme vir die bogenoemde groepe behoort in aanmerking geneem te word dat hulle op verskillende vlakke van en oor 'n verskeidenheid vaardighede, kwalifikasies en ondervinding beskik (Whitepaper on the Transformation of the Public Service, 1995:13). Formeel geskoolde en kundige lede van die voorheen benadeelde groepe, behoort oor die algemeen nie verdere opleiding anders as oriënterings- en induksieprogramme te deurloop nie. Diegene wat egter potensiaal toon, maar nie oor die nodige vaardighede, kwalifikasies en ondervinding in bepaalde rigtings beskik nie, behoort aan intensiewe en versnelde programme onderwerp te word.

Die President, mnr Nelson Mandela, huldig die volgende standpunt oor regstellende aksie:

"The primary aims of affirmative action must be to redress the imbalances created by apartheid ... it must be based on patently just, and whenever possible, universally agreed, criteria of entitlement and redress, and be implemented according to widely acceptable and clearly equitable procedures ... the goal of affirmative action will be truly to achieve equal chances for all, and amount neither to a vengeful turning of the tables of oppression, or the creaming of the country by a small new class of exploiters" (Mandela, 1991). 


\section{OOGMERKE MET REGSTELLENDE AKSIE}

Regstellende aksie behoort dus nie 'n heksejag of voortgesette diskriminasie te behels nie, maar eerder 'n program wat op gelyke geleenthede en die bemagtiging van ' $n$ bepaalde groep ingestel is.

Wingrove (1993:5) beweer dat regstellende aksie onder meer die volgende oogmerke het:

(a) die fokus val op die ontwikkeling en die bevordering van 'n benadeelde groep persone;

(b) wetgewing, 'n kwotastelsel en die stel van tydskale vir die implementering van regstellende aksie kan daargestel word;

(c) bepaalde posisies en betrekkings wat voorheen buite die bereik van die benadeelde groep was, word geïdentifiseer en indiensstellingsprosedures, opleidings- en ontwikkelingsprogramme word geloods;

Regstellende aksie is dus 'n metode waarmee gepoog word om bepaalde personeelgroepe, waarteen in die verlede gediskrimineer is, 'n geleentheid te bied om werksgeleenthede en loopbaanontwikkelingsgeleenthede in instellings te bekom. Die aard van die diskriminasie teenoor die bepaalde personeelgroepe is wydlopend. Diskriminasie kan die vorm aanneem van inter alia indiensnemingsbeleid, wat daarop ingestel is om eerder aan ' $n$ bepaalde rassegroep of geslag, voorkeur te verleen tydens 'n werwing- en keuringsproses, of dit kan daarop afgespits wees om ontwikkelingsgeleenthede en loopbaanbevorderingsgeleenthede aan slegs 'n uitgesoekte groep personeellede te bied.

Met die inwerkingstelling van die Grondwet van die Republiek van Suid Afrika, 1993 (Wet 200 van 1993) en later die Grondwet van die Republiek van Suid Afrika, 1996 (Wet 108 van 1996) is die diskriminerende praktyke van die verlede statutêr verbied. Die Grondwet van die Republiek van Suid Afrika, 1996 (Wet 108 van 1996) stipuleer in die Handves van Menseregte (hoofstuk 2) dat ras, geslag en geloof kriteria is in terme waarvan nie teenoor persone gediskrimineer mag word nie. Artikel 9(2) van die Grondwet van die Republiek van Suid Afrika, 1996 (Wet 108 van 1996) stipuleer egter dat die bereiking van gelykheid met behulp van byvoorbeeld wetgewende maatreëls, bewerkstellig kan word. Sodanige wetgewing kan daargestel word vir die beskerming en ontwikkeling van persone of kategoriee persone wat in die verlede deur diskriminerende maatreëls benadeel is. Die Regering het in terme hiervan 'n beleid van regstellende aksie van stapel gestuur. Die implikasie hiervan is dat bepaalde persone of kategorieê 
persone voortaan daarop geregtig sou wees om aanspraak te maak op voorkeurgeleenthede, in soverre dit werksgeleenthede en loopbaanontwikkeling en loopbaanvordering aanbetref. Die Wet op Arbeidsverhoudinge, 1995 (Wet 66 van 1995) bepaal byvoorbeeld dat werkgewers diensbeleid en praktyke mag handhaaf wat daarop afgespits is om personeellede of personeelgroepe waarteen in die verlede gediskrimineer is, te beskerm en te bevoordeel ten einde uiteindelike gelykheid te bewerkstellig. Die doel hiermee is om benadeelde persone sosiaal-ekonomies te bemagtig en op te hef sodat hulle na afloop van die regstellende aksietermyn as gelykes kan meeding om loopbaangeleenthede.

Regstellende aksie beïnloed egter plaaslike regerings in terme van hulle hulpbronaanwending, funksie-uitvoering en bestuur. Die afleiding kan gevolglik gemaak word dat bestuurders in plaaslike regerings in Suid Afrika voor die uitdaging staan om regstellende aksieprogramme te implementeer met inbegrip van die finansiële beperkinge op hulle onderskeie instellings en volgehoue doeltreffende dienslewering aan die gemeenskap. Regstellende aksie is daarop afgespits om bepaalde veranderinge in die personeelstruktuur van plaaslike regerings te bewerkstellig en behoort gevolglik doeltreffend bestuur te word ten einde die sukses daarvan te verseker.

Normatiewe en empiriese navorsing is gevolglik onderneem deur dwingende maatreëls wat deur die Regering ingestel is om gelyke werks- en vorderingsgeleenthede vir voorheen benadeelde persone en kategorieë persone te verseker, te ondersoek. Die Nasionale Arbeidsverhoudingeforum vir Plaaslike Regering se Gids vir die Praktiese Implementering van die Ooreenkoms oor Gelyke Indiensnemingspraktyke en Regstellende Aksie in Plaaslike Regering, die Organisatoriese Transformasie-dokument van die Instituut vir Munisipale Bestuur in Suider Afrika en regstellende aksiebeleidsdokumente van die Groter Johannesburg Metropolitaanse Oorgangsraad en die Stadsraad van Pretoria , is ondermeer tydens hierdie navorsing geraadpleeg. Die gevolgtrekking waartoe geraak word, is dat ' $n$ breë riglynmodel ontwikkel kan word vir die strategiese implementering van regstellende aksie in plaaslike regering. Die strategiese regstellende aksiemodel mag vir bestuurders en besluitnemers in plaaslike regering in Suid Afrika nuttig wees tydens die beplanning en implementering van hulle onderskeie regstellende aksieprogramme.

\section{REGSTELLENDE AKSIE AS ‘N STRATEGIESE BESTUURSPROGRAM}

Strategiese bestuur behels die aktiwiteite betrokke by die formulering en implementering van strategieë om 'n instelling se doelwitte te bereik (Thompson en Strickland, 1989: 4). Regstellende aksie word tans deur verskeie instellings 
geïmplementeer as ' $n$ veranderingsproses waartydens 'n personeelkorps daargestel behoort te word wat verteenwoordigend van die bevolkingsame-stelling van die land is, (Reddy ed., 1996: 99).

Strategiese bestuur bestaan volgens Thompson en Strickland (1989: 12) uit die volgende aantal opeenvolgende stappe: Die eerste stap is om as deel van die beplanningsfase ' $n$ visie en 'n missie in die betrokke instelling te ontwikkel. Die tweede stap behels dat lang- en korttermyndoelwitte in die instelling gestel word. Die derde stap behels die ontwikkeling van die strategie in die instelling. Tydens die vierde stap word die strategie geïmplementeer en tydens die vyfde stap word die proses herevalueer en word indien nodig, veranderings aan die missie, doelwitte en strategie gemaak (Thompson en Strickland, 1989: 12).

\section{STRATEGIESE BESTUUR EN DIE EIESOORTIGHEID VAN PLAASLIKE REGERINGSINSTELLINGS}

Strategiese bestuur, soos dit in die privaatsektor en die openbare sektor toepassing vind, verskil van mekaar. Die verskille in die strategiese bestuursprosesse is as gevolg van die onderlinge eiesoortigheid van die privaatsektor en die openbare sektor. Privaatsektororganisasies is op winsbejag ingestel en doelwitte in hierdie verband is gevolglik maklik kwantifiseerbaar. Openbare sektorinstellings, daarenteen, is op gemeenskapsdienslewering ingestel en kan nie in alle gevalle die diensleweringsmotief geredelik kwantifiseer nie. 'n Vername aspek wat die openbare sektorinstellings eiesoortig maak, is dat hulle in ' $n$ politieke omgewing funksioneer en dat hulle deur belastinggeld van die gemeenskap befonds word (Reddy ed., 1996:96).

Verskeie teoretiese en praktiese strategiese bestuursmodelle word tans in plaaslike regeringsinstellings toegepas. 'n Vername vertrekpunt by die strategiese bestuur van regstellende aksie is dat die besondere omstandighede en behoeftes wat heersend in 'n bepaalde plaaslike regeringsinstelling is, die soort strategiese benadering wat gevolg word, behoort te bepaal. Die strategiese regstellende aksie bestuursmodel en die inhoud daarvan, word dus met inbegrip van die unieke omstandighede in die onderskeie plaaslike regeringsinstellings bepaal. Die unieke omstandighede van die onderskeie plaaslike regerings-instellings, word vasgestel tydens die beplanning van die regstellende aksieproses deur inter alia met die belangegroepe te onderhandel, die regstellende aksie-oudit te ondemeem en om 'n korporatiewe klimaatsondersoek oor die heersende korporatiewe kultuur, uit te voer (Regstellende Aksie-adviseur, Stadsraad van Pretoria, 1996). 
Plaaslike regerings wat strategiese bestuursprogramme toepas, stel hulle bestuurders in staat om die omgewing waarin die instelling funksioneer, se toekoms te antisipeer, te vertolk en te vorm. Tydens die strategiese beplanningsproses word bepaalde sterkpunte en swakpunte van die betrokke instelling geïdentifiseer en word geantisipeerde geleenthede en bedreigings in die omgewing (en omgewingskragte), wat op die instelling inwerk, vertolk (Staal, 1994: 147). 'n Visie en missie word opgestel ten einde aan die plaaslike regeringsinstelling 'n toekomsstrewe te verskaf. Die sterkpunte, swakpunte, geleenthede en die bedreigings van 'n betrokke plaaslike regeringsinstelling behoort ook bepalend te wees van die aard en inhoud van die gekose strategiese bestuursprogram. Die strategie word gevolglik rondom die visie en missiestelling ontwikkel, om sodoende sinvolheid en rigting aan die strategiese proses te verleen.

\section{DIE ROL VAN BESTUURDERS IN PLAASLIKE REGERING TYDENS DIE IMPLEMENTERING VAN REGSTELLENDE AKSIE}

Strategiese beplanning en bestuur van regstellende aksie in plaaslike regering vereis dat bestuurders oor bepaalde noodsaaklike vaardighede behoort te beskik. Bestuurders behoort te begryp dat die gemeenskapsbehoeftes wat plaaslike regerings behoort te dien, en die tekort aan hulpbronne, veroorsaak dat buitengewone eise aan personeellede gestel word wanneer regstellende aksie in plaaslike regeringsinstellings toegepas word (Regstellende aksie-adviseur, Groter Johannesburg Metropolitaanse Oorgangsraad: 1996). Plaaslike regerings wat strategiese regstellende aksieprogramme implementeer, behoort dus buitengewone ondersteuning aan bestuurders en personeellede te bied. 'n Vername rol van bestuurders tydens die suksesvolle implementering van regstellende aksie is dat hulle onomwonde steun aan die regstellende aksieprogram behoort te betuig (Human, 1993: 54 en 56). Personeellede behoort daarvan bewus te wees dat hulle bestuurders en gevolglik diegene wat aan hulle leiding verskaf, die regstellende aksieproses openlik ondersteun. 'n Positiewe korporatiewe klimaat ten aansien van regstellende aksie is dus bevorderlik vir die sukses daarvan.

Regstellende aksie bring mee dat bestuurders toenemend bevel behoort te voer oor 'n heterogene personeelkrops. Die diversiteit van personeellede en groepe, elk met 'n besondere agtergrond en verwysingsraamwerk, bring mee dat bestuurders in gedagte behoort te neem dat hulle kommunikasie en bestuurstyle dienooreenkomstig behoort aan te pas. Beide empiriese en normatiewe navorsing het getoon dat bestuurders in 'n regstellende aksiemilieu, personeel behoort te kan motiveer, hulle behoort effektief te kan kommunikeer en hulle behoort oor die kennis en vermoë te beskik om teenstand teen verandering te kan hanteer. Die 
ideaal is dat alle bestuurders leiers behoort te wees. Tydens die onsekerheid wat in instelling met die implementering van 'n regstellende aksieprogram heers, behoort bestuurders as voorbeeld te dien en hulle ondergeskikte personeellede te kan motiveer. 'n Vername bestuursaspek wat deurentyd na vore tree, is dat bestuurders in plaaslike regeringsinstellings 'n deelnemende bestuursbenadering behoort te volg. Die rede hiervoor is dat die veranderingsproses ten eerste gelegitimiseer behoort te word deur middel van die ondersteuning van alle personeellede. Die personeel se ondersteuning van die veranderingsproses kan slegs vekry word indien hulle deel het in die beplanning en bestuur van die verandering. Ten tweede word die personeel deur middel van die deelnemende bestuursproses van noodsaaklike inligting rakende die veranderingsproses voorsien, wat deursigtigheid in die funksionering van die betrokke instellings bevorder (Regstellende aksie-adviseur, Stadsraad van Pretoria: 1996). Personeellede wat dus deeglik oor die regstellende aksieproses ingelig is, behoort minder vrese en bekommemisse oor hulle loopbaanvooruitsigte te hê. 'n Deelnemende bestuursbenadering in plaaslike regeringsinstellings behoort teenstand teen verandering te verminder en gevolglik die regstellende aksieproses te bevorder. Die bestuurders in plaaslike regeringsinstellings speel dus 'n sleutelrol in die suksesvolle implementering van strategiese regstellende aksie programme.

\section{DE STRATEGIESE BESTUUR VAN REGSTELLENDE AKSIE IN PLAASLIKE REGERING: 'n MODEL}

Die klem behoort tydens die ontwikkeling van 'n strategiese regstellende aksieprogram geplaas te word op die eiesoortige omstandighede en behoeftes wat heersend in die onderskeie plaaslike regerings is. 'n Strategiese bestuursproses behoort nie as ' $n$ teoretiese proses gesien te word wat noodwendig volgens ' $n$ bepaalde aantal opeenvolgende stappe verloop nie. Plaaslike regerings se unieke omstandighede en behoeftes behoort tydens die ontwerp van 'n strategiese regstellende aksiebestuursprogram in gedagte geneem te word. Die riglynmodel vir die strategiese bestuur van regstellende aksie in die plaaslike regerings word in figuur 1 geillustreer. Die Regstellende aksieprogram word telkens as ' $n$ strategie getipeer ten einde die klem te plaas op die strategiese bestuursaard daarvan.

Verwikkelinge op die politieke, ekonomiese, sosiale en tegnologiese terreine in die omgewing, lei daartoe dat plaaslike regerings hulle daarby behoort aan te pas. Die rede hiervoor is dat plaaslike regerings instellings is wat uitsluitlik daarop ingestel behoort te wees om gemeenskapsbehoeftes te bevredig. Plaaslike regerings behoort dus sensitief te wees ten opsigte van enige verandering wat 
voorkom, in die omgewing waarin hulle funksioneer. Indien plaaslike regerings nie by die omgewingskragte skik nie, mag die gevolg wees dat hulle nie aan hulle diensideaal teenoor die gemeenskap getrou bly nie.

$\mathrm{Na}$ afloop van die verkiesings op nasionale en provinsiale regeringsvlak in 1994 en die plaaslike regeringsverkiesing in 1995, het bepaalde politieke, sosiale en ekonomiese omgewingskragte regstellende aksie op plaaslike regeringsvlak genoodsaak. Die Regering het as gevolg hiervan bepaalde regstellende aksiewetgewing geformuleer en verskeie beleidsdokumente en 'n arbeidsforumooreenkoms vir regstellende aksie in plaaslike regerings is ontwikkel. In terme van hierdie dokumente kan 'n regstellende aksieprogram, gebaseer op 'n strategiese bestuursproses, vir plaaslike regering ontwikkel word.

Die stappe in die model, soos in Figuur 1 supra aangetoon, kan soos volg verklaar word:

\section{Stap 1: Ontwikkel 'n visie en 'n missie vir regstellende aksie}

Die eerste stap van die strategiese bestuursproses vir regstellende aksie in plaaslike regerings behels die voorlopige ontwikkeling van 'n visie en 'n missie vir regstellende aksie. Plaaslike regerings behoort as deel van strategiese beplanning oor ' $n$ visie en 'n missie vir regstellende aksie te beskik. Hierdie fase word as die beplanningsfase vir die implementering van die regstellende aksieproses getipeer.

'n Voorlopige regstellende aksie-ondersoekspan, bestaande uit plaaslike raadslede, bestuurders en personeellede van 'n bepaalde plaaslike regering word aangestel om 'n voorlopige ondersoek te loods, wat as 'n regstellende aksieterreinverkenningsproses beskou kan word. Die strategiese regstellende aksiebestuursproses behoort in deurlopende konsultasie met georganiseerde plaaslike regering, die Instituut vir Munisipale Bestuur in Suider Afrika, konsultante, academici en ander plaaslike regerings plaas te vind. Die rede vir die deurlopende konsultasie is om te put uit die ondervinding en kennis van spesialiste op die gebied van strategiese bestuur en regstellende aksie. Voortvloeiend uit die voorlopige regstellende aksie-ondersoekspan se aktiwiteite, behoort ' $n$ konsultatiewe forum geskep te word om onderhandelinge met bepaalde belanghebbendes oor die implementering van die regstellende aksie te voer. Die konsultasieforum se werksaamhede kan die vorm aanneem van werkswinkels en seminare om sodoende alle belangstellende persone of groepe persone by die regstellende aksieproses te betrek. 'n Vername funksie van die konsultatiewe forum is om alle belanghebbendes wat 'n legitieme belang by die regstellende aksieproses in 'n bepaalde plaaslike regering het, te identifiseer. Die regstellende 
aksieproses sal nie suksesvol deurgevoer kan word, alvorens almal wat daarin 'n belang het, nie deel van die proses gemaak word nie.

Figuur 1: 'n Model vir die Strategiese Bestuur van Regstellende Aksie in Planslike Regerings

STAP I

ONTWIKKEL ' $n$ VISIE EN

'N MISSIE VIR REGSTEL-

LENDE AKSIE

STAP2

STEL KORT- EN LANG-

TERMYN DOELWITTE VIR

REGSTELLENDE AKSIE

STAP 3

ONTWIKKEL 'N REGSTEL-

LENDE AKSIESTRATEGIE

STAP4

IMPLEMENTEER DIE

REGSTELLENDE

AKSIESTRATEGIE

STAP 5

EVALUERING EN

MOONTLIKE AANPASSING

VAN DIE REGSTELLENDE

AKSIESTRATEGIE

Die konsultatiewe forum vir regstellende aksie behoort voorts die aanstelling van 'n regstellende aksiekomitee te fasiliteer. Die regstellende aksiekomitee behoort te bestaan uit verteenwoordigers van alle belangegroepe by die regstellende aksieproses, insluitend politieke ampsbekleërs, bestuurders en personeellede in 'n bepaalde plaaslike regering. Die regstellende aksiekomitee moet 'n regstellende aksie-adviseur aanstel wat daarvoor verantwoordelik sal wees om die regstellende aksieproses in die bepaalde plaaslike regering te lei. Die regstellende aksieadviseur sal 'n bekwame persoon wees wat verkieslik kennis dra van regstellende aksie, strategiese bestuur en plaaslike regering. Aangesien die regstellende aksieadviseur 'n sleutelrol in die suksesvolle implementering en deurvoering van die 
regstellende aksieproses speel, is dit noodsaaklik dat die persoon die volle ondersteuning van die regstellende aksiekomitee geniet.

Die regstellende aksie-adviseur is verantwoording aan die regstellende aksiekomitee verskuldig en behoort direk aan die hoofuitvoerende beampte van die betrokke plaaslike regering te rapporteer. Aangesien regstellende aksie so ' $n$ vername proses in plaaslike regering is, moet die keuse op ' $n$ regstellende aksieadviseur ook die volle ondersteuning van die plaaslike raad te geniet.

Die regstellende aksiekomitee, waarvan die hoofuitvoerende beampte en die regstellende aksie-adviseur lid is, kan verskeie alternatiewe metodes en benaderings ondersoek met behulp waarvan die veranderingsproses in die betrokke plaaslike regering kan plaasvind. Hierdie ondersoek kan met behulp van georganiseerde plaaslike regeringsinstellings, die Instituut vir Munisipale Bestuur in Suider Afrika, konsultante, akademici en ander plaaslike regerings plaasvind, ten einde voldoende inligting oor die veranderingsproses in plaaslike regering te bekom.

'n Regstellende aksie-oudit sal deur 'n konsultant uitgevoer word wat deur die regstellende aksiekomitee aangestel is. Die regstellende aksie-oudit is 'n kritiese ondersoek na die heersende personeelbeleid en -prosedures in 'n betrokke plaaslike regeringsinstelling. Die doel van die regstellende aksie-oudit, is om enige diskriminerende praktyke wat in 'n plaaslike regeringsinstelling mag voorkom te identifiseer. 'n Personeelprofiel word opgestel om aan te dui hoe verteenwoordigend ' $n$ plaaslike regeringsinstelling van die gemeenskap wat bedien word, is en welke regstellende aksiemaatreëls dus nodig is. ' $n$ Korporatiewe klimaatsondersoek word ter gelyke tyd uitgevoer om die beskouinge van die personeel oor regstellende aksie te toets. Die inligting wat tydens die regstellende aksie-oudit ingesamel word, is noodsaaklik vir die beplanning van die regstellende aksieproses. Indien die korporatiewe klimaatsondersoek daarop dui dat die heersende korporatiewe kultuur van 'n plaaslike regeringsinstelling oorwegend negatief teenoor regstellende aksie is, kan die nodige intervensies geloods word om die personeel beter op die verandering voor te berei en hulle beskouinge te verander.

Onderwyl die beplanning vir regstellende aksie onderweg is, behoort plaaslike regeringsinstellings steeds daarop bedag te wees om hulle hoofsaaklike funksie, naamlik kwaliteit dienslewering aan die gemeenskap, uit te voer. Regdeur die implementering van die regstellende aksieproses behoort dienslewering telkens voorrang bo ander plaaslike regeringsaktiwiteite te geniet. Die ideaal is om die standaard van dienslewering aan die gemeenskap met behulp van die regstellende aksiemaatreëls te verbeter. 
Stap 2 en 3: Stel lang- en korttermyndoelwitte en ontwikkel 'n regstellende aksiestrategie

Tesame met die ontwikkeling van 'n visie en 'n missie vir regstellende aksie in plaaslike regerings, behoort lang- en korttermyndoelwitte ontwikkel te word sodat konkrete mylpale vir regstellende aksie vasgestel kan word. Hierdie langen korttermyndoelwitte behoort duidelik gestel te word en haalbaar te wees. Alle belanghebbendes in die onderskeie plaaslike regeringsinstellings behoort tydens die strategiese bestuursproses deurlopend van inligting voorsien te word oor vordering wat met doelwitbereiking gernaak word.

Die doelwitstellingsproses behoort 'n konsultatiewe proses te wees en onderhandelinge behoort met alle interne en eksterne belanghebbendes van die onderskeie plaaslike regeringsinstellings gevoer te word. Indien alle belangegroepe nie by die doelwitstellingsproses betrek word nie, mag die gevolg wees dat onrealistiese doelwitte gestel word, wat die regstellende aksieproses sal benadeel.

Die onderhandelinge wat met die belangegroepe in plaaslike regering oor doelwitte gevoer word, kan met behulp van die dinkskrumtegniek ondersteun word. Die dinkskrumtegniek behels dat diegene wat as sleutelpersone tydens die beplanning van die regstellende aksieproses beskou word, op 'n geleë tyd en plek afgesonder word en 'n dinkskrum vorm om met voorstelle vorendag te kom. Hierdie voorstelle word dan aan die regstellende aksiekomitee voorgelê vir evaluering. Die dinkskrumspan behoort met behulp van inligting wat tydens die regstellende aksie-oudit en die korporatiewe klimaatsondersoek bekom is, bepaalde voorstelle rakende die strategiese proses, die finale visie en missie en moontlike regstellende aksieteikens en kwotas te maak. Die gevolg van die korten langtermyn doelwitstellingsproses behoort te wees dat 'n onderhandelde ooreenkoms oor regstellende aksie bereik word. 'n Regstellende aksiebeleid word geformuleer wat vervat behoort te word in 'n regstellende aksiebeleidsverklaring. Die doel met die regstellende aksiebeleidsverklaring is om aan alle belanghebbendes ' $n$ dokument te bied waarin hulle detailinligting kan bekom oor regstellende aksie in ' $n$ bepaalde plaaslike regering en die verloop van die betrokke regstellende aksieproses. Die regstellende aksiebeleidsverklaring neem die vorm aan van 'n kontraktuele ooreenkoms tussen die onderhandelingsvennote en is gevolglik ' $n$ dokument met regstatus. Deurlopende konsultasie behoort regdeur die lang- en korttermyn doelwitstellingsproses met kundige persone gevoer te word sodat verseker kan word dat die regstellende aksieproses wat ontwikkel word aan alle wetlike vereistes voldoen en dat geput kan word uit andere se ervaring. 


\section{Stap 4: Implementeer die regstellende aksiestrategie}

Die regstellende aksieprogram kan na afloop van die beplanningsfase geimplementeer word. Die implementering van die strategiese regstellende program behoort te voldoen aan alle voorskrifte wat in wetgewing, arbeidsforumooreenkomste en die regstellende aksie-ooreenkoms van die bepaalde plaaslike regeringsinstelling, gestel word. Plaaslike regeringsinstellings behoort daarop bedag te wees dat die normale plaaslike regeringsfunksies steeds tydens die implementering van die strategiese regstellende aksieproses behoort voort te gaan. Volgehoue kwaliteit dienslewering aan die gemeenskap behoort steeds die hoofdoelwit van die instelling te wees. Die hulpbronne wat vir die implementering van regstellende aksie geallokeer word, behoort steeds doeltreffend aangewend te word. Deurlopende konsultasie behoort steeds met kundige persone plaas te vind aangesien die implementering van die regstellende aksieprogram 'n kritieke deel van die regstellende aksieproses is.

Intervensies word tydens hierdie fase in die funksionele aktiwiteite van die plaaslike regeringsinstellings geloods. Strukture, personeelstelsels, prosesse en bestuurstegnieke, is aspekte wat ondermeer deur die intervensies beïnvloed word. Bestuurders in plaaslike regeringsinstellings vervul 'n vername rol gedurende die implementering van die regstellende aksieprogram. Die bestuurders is diegene wat in die werksplek die veranderingsproses behoort te bestuur, behulpsaam behoort te wees om die korporatiewe kultuur te verander en daarvoor verantwoordelik is om konflik tussen die personeel te hanteer.

\section{Stap 5: Evalueer die regstellende aksiestrategie}

'n Strategiese bestuursproses behoort sodanig te funksioneer dat daar tydens enige stap van die proses, 'n verandering aan die strategiese doelwitte gemaak kan word sonder dat die hele proses benadeel word. Tydens die strategiese bestuursproses word 'n deurlopende evaluering gedoen oor doelwitbereiking en of die onderskeie stappe suksesvol deurgevoer is. Die finale stap in die strategiese proses behels egter 'n evalueringsproses om vas te stel hoe suksesvol die totale strategiese regstellende aksieprogram was. Die geleentheid word gebied om die hele proses in heroënskou te neem en, indien nodig, veranderings aan te bring. Bestuurders behoort tydens hierdie stap vas te stel of die strategie uiteindelik identifiseerbaar was in terme van die verandering wat in die prosesse, korporatiewe kultuur en dienslewering van die instelling meegebring het. 'n Suksesvolle strategie behoort ook gemeet te word aan die mate waartoe dit voldoen aan die kriteria wat die omgewingskragte dikteer. 
Die evalueringsproses word uitgevoer met behulp van 'n verdere regstellende aksie-oudit en periodieke korporatiewe klimaatsondersoeke. 'n Vername komponent van die evalueringsproses is om terugvoer aan die belanghebbendes te verskaf ten opsigte van doelwitbereiking. Terugvoer is veral noodsaaklik vir bestuurders en personeellede aangesien hulle ' $n$ aanduiding behoort te kry oor hulle werkverrigting in terme van die strategiese regstellende aksiedoelwitte wat vir hulle gestel is. Die uiteindelike gevolg van die strategiese regstellende aksieproses behoort te wees om in personeelkorps te bekom wat verteenwoordigend is van die bevolkingsamestelling van die bepaalde gebied en om die werkplek te verdemokratiseer. Dienslewering aan die gemeenskap behoort uiteindelik verbeter te word indien die voomoemde bree doelwitte met behulp van die strategiese regstellende aksiebestuursproses bereik is.

\section{GEVOLGTREKKING}

Die Suid Afrikaanse Regering beskou regstellende aksie as ' $n$ vername metode waardeur diskriminerende loopbaanpraktyke wat deur die vorige politieke dispensasie teenoor Swartes, Bruinmense, Indiërs, vroue en gestremdes gevolg is, reg te stel. Wetgewing en regstellende aksiebeleidsdokumente wat vir regstellende aksie in instellings voorsiening maak, is geformuleer. Plaaslike regerings behoort gevolglik ook regstellende aksie te implementeer. Regstellende aksie plaas egter addisionele druk op hulpbronne en bestuurders in instellings behoort te verseker dat sodanige programme doeltreffend bestuur word.

$\mathrm{Na}$ afloop van normatiewe en empiriese navorsing is bevind dat dit moontlik is om regstellende aksie in plaaslike regering in terme van ' $n$ strategiese proses te bestuur. In hierdie artikel is ' $n$ riglynmodel ontwikkel in terme waarvan strategiese regstellende aksieprogramme suksesvol bestuur kan word.

\section{VERWYSINGS}

1. ADAMS, C. ed. 1993. Affirmative Action in a Democratic South Africa. Kenwyn: Juta \& $\mathrm{Co}$, Ltd.

2. ANDREWS, Y. (1992). "Affirmative Action: A Suspected Equaliser". SAIPA. 27(1): 34.

3. ANON. (1993). Development and Democracy. "Affirmative Action in India, Malaysia, Sri Lanka and the USA". Vol 6 (September).

4. ANON. Nasionale Arbeidsverhoudingeforum vir Plaaslike Regering. (1994). Gids vir die Praktiese Implementering van die Ooreenkoms oor Gelyke Indiensnemings-praktyke en Regstellende Aksie in Plaaslike Regering.. Dokument. 
5. Groter Johannesburg Metropolitaanse Oorgangsraad. (1996). Regstellende Aksie- en Gelyke Indiensnemingsgids. Dokument.

6. HUMAN, L. (1993). Affirmative Action and the Development of People. Kenwyn: Juta \& Co, Ltd.

7. Instituut vir Munisipale Bestuur. (1996). (Instituut vir Munisipale Bestuur van Suider Afrika). Organisatoriese Transformasie. Dokument.

8. MADI, P. M. (1993). Affirmative Action in Corporate South Africa. Surviving in the Jungle. Kenwyn: Juta \& Co, Ltd.

9. Mandela, N. R. (1991). Toespraak.

10. Reconstruction and Development Programme. (1994). African National Congress. Johannesburg: Umanyo Publishers.

11. REDDY, P. S. ed. (1996). Readings in Local Government Management and Development. A Southern African Perspective. Kenwyn: Juta \& Co, Ltd.

12. Regstellende Aksie-adviseur. (1996). Groter Johannesburg Metropolitaanse Oorgangsraad. Persoonlike Onderhoud.

13. Regstellende Aksie-adviseur. (1996). Stadsraad van Pretoria. Persoonlike Onderhoud.

14. SMIT, P. J. \& CRONJE, G. J. de J. (eds.) (1992). Management Principles. A Contemporary South African Edition. Kenwyn: Juta \& Co, Ltd.

15. South Africa (Republic). (1995). Whitepaper on the Transformation of the Public Service.

16. STAAL, F. H. (1994). A Strategic Management Process for Commercialisation and Privatisation in the Public Sector. University of Pretoria, Pretoria: Unpublished Doctoral Thesis.

17. Stadsklerk. Stadsraad van Pretoria. Persoonlike Onderhoud.

18. Stadsraad van Pretoria. Regstellende Aksie-ooreenkoms. (1995). Dokument.

19. Suid Afrika (Republiek). (1996). Grondwet van die Republiek van Suid Afrika. (Wet 108 van 1996).

20. Suid Afrika (Republiek). (1993). Grondwet van die Republiek van Suid Afrika. (Wet 200 van 1993).

21. Suid Afrika (Republiek). (1995). Wet op Arbeidsverhoudinge. (Wet 66 van 1995).

22. THOMPSON, A. A. \& STRICKLAND, A. J. (1989). Strategic Formulation and Implementation. Illinois: BPI Irwin.

23. WINGROVE, T. (1993). Affirmative Action. A "How To" Guide for Managers. Randburg: Knowledge Resources.

24. Working Paper of the Constitutional Development Service. (1993). Dokument. 